\title{
Evaluating Patients' Preferences for Dulaglutide versus Insulin Glargine Medication Proffles in T2D Patient Subgroups
}

Vivian T. Thieu, PhD1, Jiat-Ling Poon, PhD², Heather Gellhorn, PhD², Syed W. Hassan, MSc ${ }^{1}$, Kirsi Norrbacka, MSc ${ }^{2}$, Kristina S. Boye, PhD Eli Lilly and Company, Indianapolis, USA; ${ }^{2}$ Evidera, Bethesda, USA

\section{OBJECTIVE}

To determine patient preferences for the treatment features, efficacy, and side effects of once weekly GLP-1 receptor agonist dulaglutide $1.5 \mathrm{mg}$ (ready-to-use pen) versus daily insulin glargine (SoloSTAR@ pen) stratified by age ( $<60$ versus $\geq 60$ years) and duration of diabetes ( $\leq 5$ versus $>5$ years)

\section{STUDY DESIGN ${ }^{1}$}

- This cross-sectional study involved in-person completion of surveys with people with type 2 diabetes (T2D), naïve to injectable treatments for diabetes, and compared participants aged $<60$ years and $\geq 60$ years, and participants with a duration of diabetes $\leq 5$ years and $>5$ years

- As part of the survey, a discrete choice experiment (DCE) examined the following 7 attributes of dulaglutide and insulin glargine treatment:

- Frequency of gastrointestinal side effects, frequency of hypoglycemia, frequency of pancreatitis, dosing frequency, $\mathrm{HbA}_{1 \mathrm{c}}$ change, weight change, and type of delivery system (ready-to-use pen for dulaglutide vs SoloSTAR $®$ device)

- Attribute selection was informed by qualitative in-person interviews and levels of attributes were based on instructions for use documentation and the results from AWARD-2

- Participants were presented with 12 sets of two hypothetical medication choices and asked to select their preferred medication profile

- One of the 12 choice pairs presented the actual medication profile for dulaglutide against the profile for insulin glargine to determine participants' direct preference between the two profiles

- Sample size was estimated using number of choice pairs, number of alternatives per choice pair and maximum number of levels for any one attribute

\section{Statistical Analysis}

- Part-worth utilities were estimated using random effects logit regression model $^{2}$ and used to calculate relative importance (RI) values for each attribute separately for each subgroup

\section{KEY RESULT}

The majority of patients preferred the dulaglutide medication proffle to the insulin glargine (SoloSTAR@ device) medication profile irrespective of age or Dulaglutide duration of diabetes

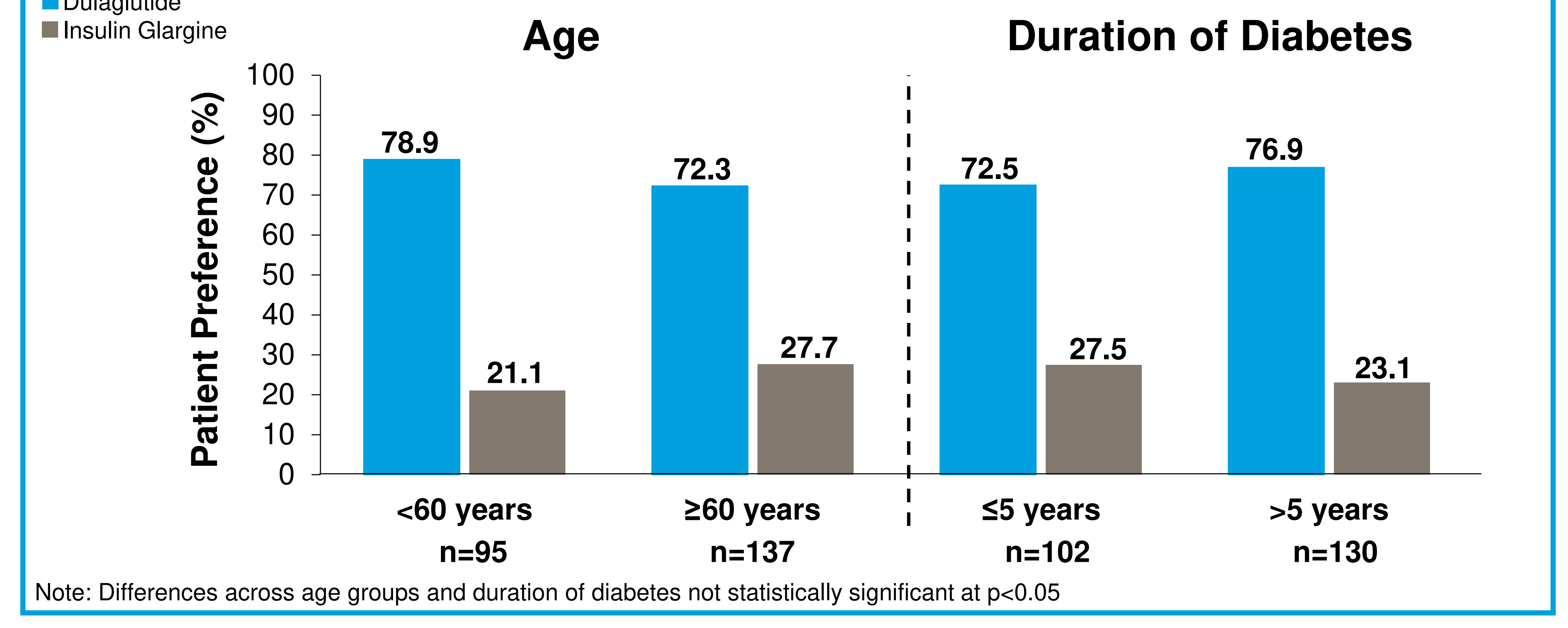

\section{CONCLUSION}

\section{Subgroup analyses demonstrated}

The majority of people preferred the dulaglutide profille to the insulin glargine (SoloSTAR@ device) proffle irrespective of age or duration of diabetes

These results will help HCPs and patients understand the clinical and non-clinical factors influencing preferences of people with T2D, naïve to injectable diabetes medications, when considering next treatment options

\section{METHODS}

Main Study Participants

- Participants from London, Edinburgh, Birmingham, and Cardiff were recruited via newspaper and magazine advertisements

- Key inclusion criteria: Male or female $\geq 18$ years of age; diagnosed with T2D; currently treated for T2D with oral medications only

- Key exclusion criteria: Current type 1 or gestational diabetes; T2D that is currently treated only with diet and exercise; previously received regular treatment with injectable medication for T2D

- T2D diagnosis was self-reported, proof of prescription of an oral medication for diabetes was provided prior to participation

\section{BASELINE CHARACTERISTICS}

Demographic and Clinical Characteristics

$\begin{array}{lc} & \begin{array}{c}\text { Overall Sample } \\ \mathbf{N}=232\end{array} \\ \text { Gender } & 172(74.1) \\ \text { Male } & 60(25.9) \\ \text { Female } & 61.8 \pm 10.8[27-87] \\ \text { Age (years), Mean } \pm \text { SD, [Range] } & 29.8 \pm 6.1[20-67] \\ \text { BMI (kg/m²), Mean } \pm \text { SD, [Range] } & 17(7.3) \\ \text { Duration of T2D } & 85(36.6) \\ \text { Less than 1 year } & 67(28.9) \\ \text { More than } 1 \text { year and up to } 5 \text { years } & 63(27.2) \\ \text { More than } 5 \text { years and up to 10 years } & 111(47.8) \\ \text { More than 10 years } & 68(29.3) \\ \text { Current T2D treatment } & 53(22.8) \\ \text { One oral diabetes medication only } & \\ \text { Two oral diabetes medication only } & \end{array}$

\section{ADDITIONAL RESULTS}

Part-Worth Utilities of Attributes and Levels Among UK T2D Patients ( $\mathrm{N}=232$ ) by Age Group ( $<60$ years vs $\geq 60$ years)

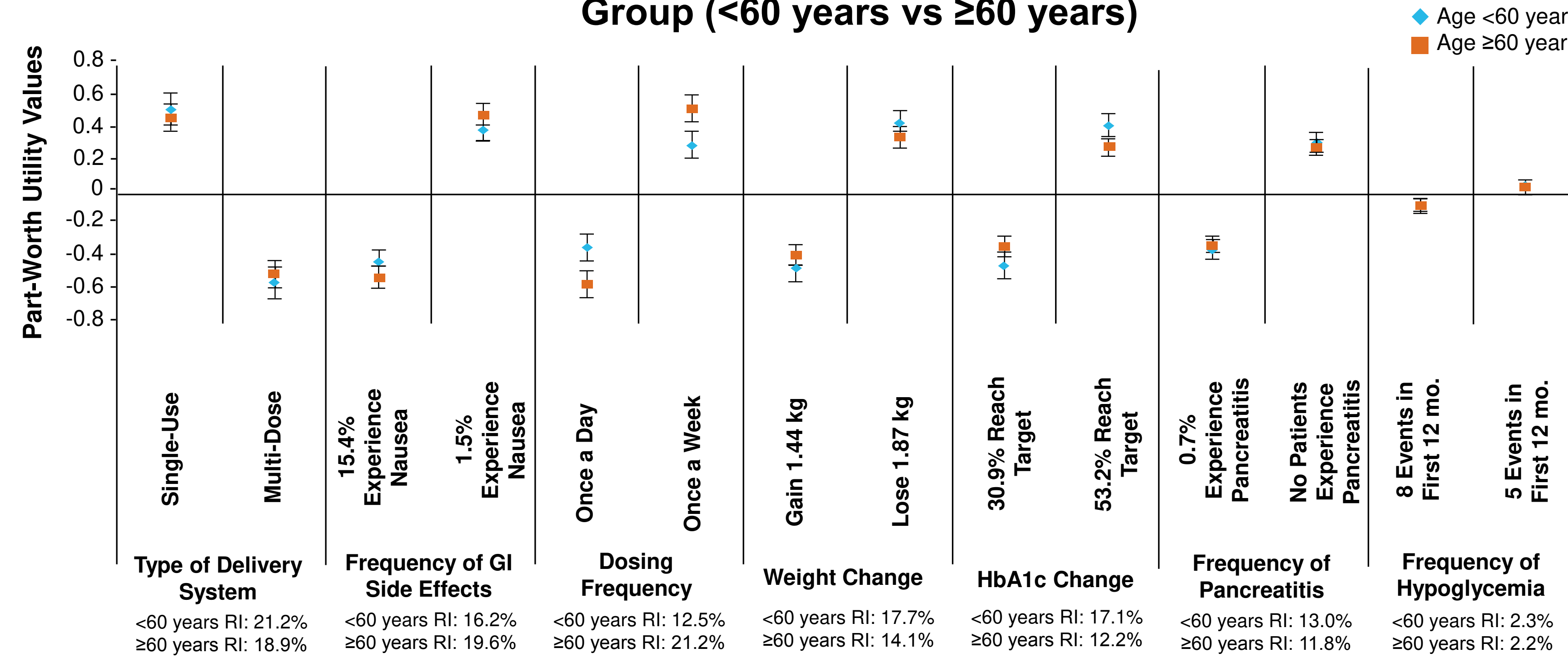

- The preferences and RI of attributes were fairly consistent across the age groups with the exception of dosing frequency, which was significantly more important among older vs younger participants $(R l=21.1 \%$, Rank $=1 \mathrm{vs}$. $\mathrm{Rl}=12.5 \%$, Rank=6; $\mathrm{p}<0.05$ ). While both groups preferred less frequent once weekly dosing, this preference was $\mathrm{Rl}=12.5 \%$, Rank $=6 ; \mathrm{p}<0.05)$. While both groups preferred
significantly stronger among the older participants $(p<0.05)$

Part-Worth Utilities of Attributes and Levels Among UK T2D Patients ( $\mathrm{N}=232)$ by Duration of Diabetes $(\leq \mathbf{5}$ years vs $>\mathbf{5}$ years)
$\begin{aligned} & \text { Duration of Diabetes } \leq 5 \text { years }(\mathrm{N}=102) \\ & \text { Duration of Diabetes }>5 \text { years }(\mathrm{N}=130\end{aligned}$

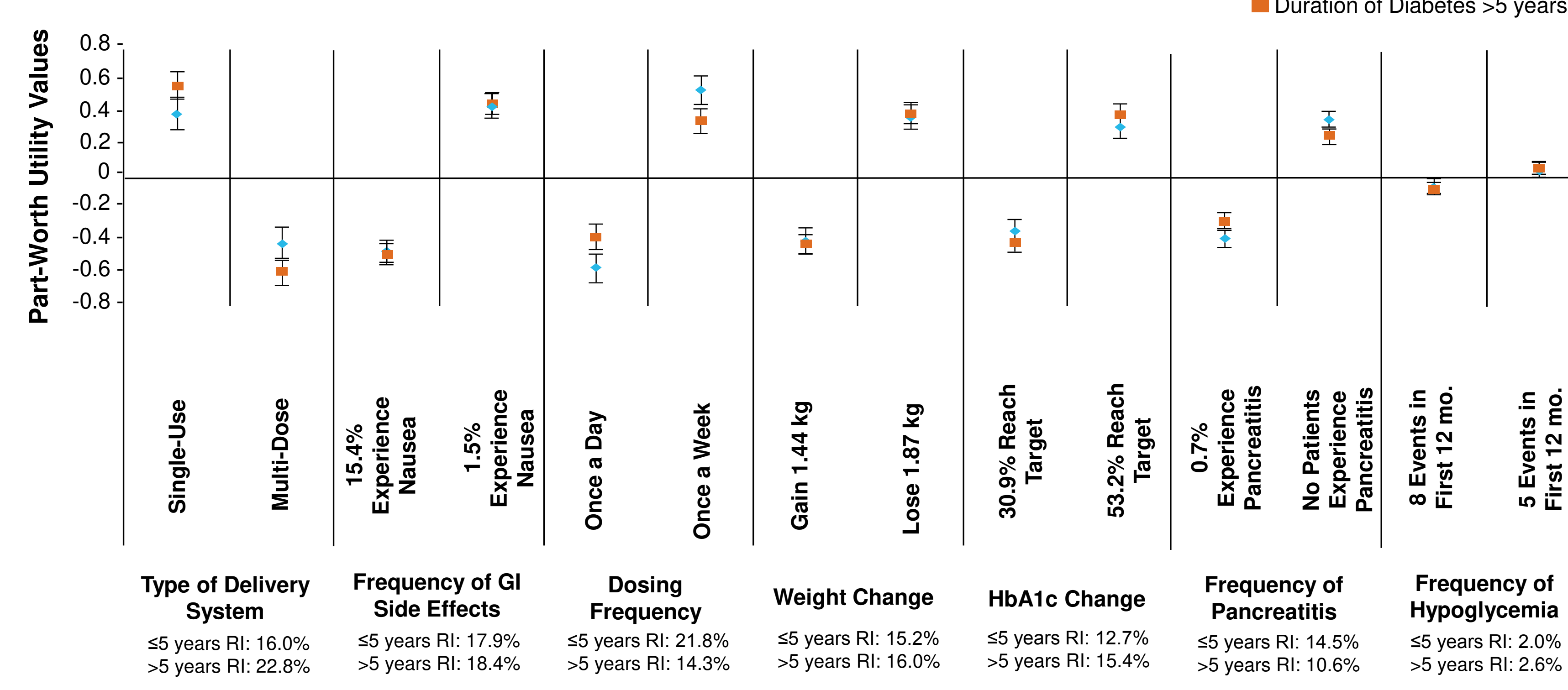

RI of attributes did not significantly differ between duration of diabetes groups; however, dosing frequency was the most important attribute to those diagnosed for $\leq 5$ years, while it ranked as the 5 th most important among patients diagnosed for $>5$ years

Limitations

- DCEs are commonly used to examine preferences for attributes of a wide-range of products and services; however, it is uncertain the degree to which the reported preferences reflect the actual preferences of patients considering real-life medication decisions or how strongly these preferences might influence their medication-related behaviors or that of their prescribing physician

- The comparisons characterized only one medication and the corresponding device from each class of interest so it is unclear the extent to which the results may be generalizable across the full range of medications within each class and the full range of delivery devices

REFERENCES

Norrbacka et al. Evaluating Patients' Preferences for Dulaglutide Versus Insulin Glargine Profiles in the
United Kingdom: A Discrete Choice Experiment. Poster presented at the ISPOR $20^{\text {th }}$ Annual European Congress; Glasgow, Scotland; November 4 - 8, 2017. PDB56

Kuhfeld WF. Marketing Research Methods in SAS. Oct 2010. SAS 9.2 Edition; 1309 pgs: Cary, NC.

Acknowledgments: The authors would like to thank Chrisanthi A. Karanikas, MSc (Eli Lilly and Company) for 